\title{
DOSES DE BORO NO DESENVOLVIMENTO DE COPO-DE-LEITE EM SOLUÇÃO NUTRITIVA
}

\author{
Boron doses in the development of calla lily in nutrient solution
}

\author{
Roseane Rodrigues de Souza ${ }^{1}$, Patrícia Duarte de Oliveira Paiva², Janice Guedes de Carvalho ${ }^{3}$, \\ Elka Fabiana Aparecida Almeida ${ }^{4}$, Juliana Caldeira Victer Barbosa ${ }^{2}$
}

\begin{abstract}
RESUMO
O boro desempenha funções importantes em processos biológicos das plantas, como a síntese e estruturação da parede celular, lignificação, metabolismo e transporte de carboidratos, além de participar da divisão e diferenciação celular em tecidos meristemáticos. No entanto, as necessidades nutricionais para o cultivo de copo-de-leite, especialmente de boro, ainda são pouco conhecidas. Assim, objetivou-se avaliar os efeitos de diferentes doses de boro no crescimento e desenvolvimento, teor e acúmulo desse nutriente em plantas de copo-de-leite cultivadas em solução nutritiva. Mudas micropropagadas foram submetidas aos tratamentos com as doses de 0,$05 ; 0,25 ; 0,50 ; 0,75 ; 1,00$ e $2,00 \mathrm{mg} \mathrm{L}^{-1}$ de boro em solução nutritiva de Hoagland \& Arnon diluída a $30 \%$ de sua força iônica. O delineamento experimental foi o inteiramente casualizado, com dez repetições. As plantas não manifestaram sintomas visuais de deficiência ou de toxidez de boro, no entanto, o sistema radicular das plantas cultivadas na dose de $0,05 \mathrm{mg} \mathrm{L}^{-1}$ de boro apresentou-se com o crescimento reduzido. A melhor dose para o desenvolvimento adequado de plantas de copo-de-leite em solução nutritiva é de $1,20 \mathrm{mg} \mathrm{L}^{-1}$ de boro.
\end{abstract}

Termos para indexação: Zantedeschia aethiopica (L.) Spreng, micronutrientes, flor de corte.

\begin{abstract}
Boron has essential functions in plant biological processes such as cell wall synthesis and structuralization, lignification, carbohydrates metabolism and transport. This element also acts in cell division and differentiation in meristematic tissues. However, the nutritional needs for calla lily cultivation, and especially boron needs, are still poorly known. Thus, the objective of this work was to evaluate the effects of different boron doses on growth and development, content and accumulation of boron in calla lily plants grown in a nutrient solution. Micropropagated seedlings were submitted to treatments with the doses $0.05 ; 0.25$; $0.50 ; 0.75 ; 1.00$ and $2.00 \mathrm{mg} \mathrm{L}^{-1}$ boron in Hoagland \& Arnon nutrient solution diluted to $30 \%$ of its ionic force. The experimental design used was completely randomized blocks with ten replicates. Plants showed no visual deficiency or toxicity symptoms, however, the root system of plants cultivated in $0.05 \mathrm{mg} \mathrm{L}^{-1}$ boron showed reduced growth. The best development of calla lily plants was observed in $1.20 \mathrm{mg} \mathrm{L}^{-1}$ boron in nutrient solution.
\end{abstract}

Index terms: Zantedeschia aethiopica (L.) Spreng, micronutrients, cut flower.

(Recebido em 18 de junho de 2009 e aprovado em 8 de abril de 2010)

\section{INTRODUÇÃO}

Recomendações sobre o manejo da nutrição e adubação para o cultivo de copo-de-leite, ainda são bastante escassas, o que tem ocasionado o uso inadequado de fertilizantes, os quais têm sido aplicados em quantidades elevadas (Silberbush \& Lieth, 2004) ou reduzidas, comprometendo o bom desenvolvimento e a produtividade da espécie.

Nutrientes essenciais devem estar prontamente disponíveis, uma vez que possuem funções indispensáveis para o adequado crescimento e desenvolvimento das plantas. Dentre esses, o boro está envolvido em muitos dos processos fisiológicos das plantas, como a síntese e estruturação da parede celular, lignificação, metabolismo e transporte de carboidratos, metabolismo de ácido indolacético (AIA), metabolismo fenólico, metabolismo de RNA, metabolismo de ascorbato, respiração, divisão celular, síntese e estruturação de células-guarda (Marschner, 1995; Malavolta, 2006; Pegoraro et al., 2008).

Ao avaliar alterações anatômicas em ápices radiculares de feijoeiro submetido a níveis de boro em solução nutritiva, Moraes-Dallaqua et al. (2000), verificaram que a omissão desse nutriente provocou inibição da divisão e alongamento celular, hipertrofia de células, desorganização de elementos vasculares em raiz, o que impediu a planta de completar o seu ciclo.

1Universidade Federal de Lavras/UFLA - Departamento de Agricultura/DAG - Cx. P. 3037 - 37200-000 - Lavras, MG - roseanersouza@yahoo.com.br ${ }^{2}$ Universidade Federal de Lavras/UFLA - Departamento de Agricultura/DAG - Lavras, MG

3Universidade Federal de Lavras/UFLA - Departamento de Ciência do Solo/DCS - Lavras, MG

${ }^{4}$ Empresa de Pesquisa Agropecuária de Minas Gerais/EPAMIG - São João Del Rei, MG 
Em paricá (Schizolobium amazonicum Huber ex Ducke), Lima et al. (2003), testando doses de boro em solução nutritiva, observaram sintomas de deficiência de boro nas folhas novas e raízes e, ainda, de toxidez nas folhas velhas, além de inibição do crescimento. Em estudo realizado por Silva et al. (2008), cultivando mamoneira sob doses de boro em solução nutritiva, verificou-se que os limbos das folhas novas na deficiência de boro apresentaram-se deformados, espessos e com necrose nos bordos foliares, e ainda, foram observados sintomas de toxidez na fase inicial do desenvolvimento foliar das plantas cultivadas na maior dose, ocorrendo clorose nos bordos, sendo que com o decorrer do tempo, essa clorose foi verificada somente nas folhas velhas.

Assim, neste trabalho, objetivou-se avaliar os efeitos de diferentes doses de boro no crescimento e desenvolvimento, teor e acúmulo de boro em copo-deleite cultivado em solução nutritiva.

\section{MATERIAL E MÉTODOS}

O experimento foi conduzido no período de abril a novembro de 2008.

As mudas utilizadas foram produzidas por micropropagação e aclimatizadas em estufa com nebulização intermitente, por 40 dias, em bandejas plásticas de 24 células contendo substrato Plantmax ${ }^{\circledR}$. As mudas foram então retiradas do substrato e as raízes foram lavadas em água corrente. Em seguida, foram transferidas para bandeja plástica de $36 \mathrm{~L}$, contendo solução completa de Hoagland \& Arnon (1950) n. ${ }^{\circ}$ 2, diluída a $20 \%$ de sua força iônica, permanecendo por 15 dias, em casa de vegetação. Após, foram transferidas para a mesma solução, diluída a $30 \%$, permanecendo por 45 dias, para adaptação.

Após a adaptação, as plantas foram transplantadas para vasos de $3 \mathrm{~L}$ e fixadas pelo caule por meio de uma placa de isopor de $25 \mathrm{~mm}$, sendo então submetidas aos tratamentos. Utilizou-se a solução nutritiva completa de Hoagland \& Arnon (1950) n. ${ }^{\circ}$ 2, a 30\% da força iônica, com exceção do ácido bórico, que foi adicionado, conforme os tratamentos, nas doses de 0,$05 ; 0,25 ; 0,50 ; 0,75 ; 1,00$ e $2,00 \mathrm{mg} \mathrm{L}^{-1}$ de boro.

A solução nutritiva foi mantida sob aeração constante durante todo o período experimental, tendo sido feito trocas quinzenalmente. No intervalo de renovação das soluções, o volume dos vasos foi completado com água deionizada, sempre que necessário.

O experimento foi mantido sob tela Sombrite ${ }^{\circledR} 50 \%$, disposta dentro da casa de vegetação. $\mathrm{O}$ delineamento experimental utilizado foi o inteiramente casualizado com 6 tratamentos, em 10 repetições e uma planta por parcela.

As características agronômicas foram avaliadas após sete meses de cultivo das plantas, sendo observados a altura das plantas; número, comprimento e largura das folhas; comprimento do pecíolo da folha; número de brotos; diâmetro do rizoma e comprimento radicular total. As medidas de comprimento e largura de folhas, comprimento de pecíolo da folha foram mensuradas na folha mais nova totalmente expandida, medidos a partir da inserção do pecíolo com o limbo foliar.

Para a obtenção do comprimento radicular total, as raízes foram digitalizadas e analisadas com o auxílio do programa computacional WinRHIZO ${ }^{\circledR}$ (Régent Instruments, 2004) e do scanner fotográfico Epson ${ }^{\circledR}$ Perfection 3200.

As inflorescências produzidas durante a condução do experimento foram colhidas quando apresentaram padrão de colheita, conforme estabelecido por Nowak \& Rudnicki (1990) e Salinger (1991), estando a espata totalmente expandida e ausente de pólen. Foram mensurados o comprimento e diâmetro da haste; a largura e comprimento da espata.

Após as avaliações agronômicas, determinaram-se as matérias frescas das folhas, separadas em limbos e pecíolos, dos rizomas e das raízes. Em seguida, essas partes das plantas foram lavadas separadamente em água corrente e, após em água destilada. Foram então acondicionadas em saco de papel kraft, identificadas e secas em estufa de circulação forçada de ar com temperatura regulada entre 65 a $70^{\circ} \mathrm{C}$ até peso constante. $\mathrm{O}$ mesmo procedimento foi adotado para as inflorescências colhidas durante o período experimental. Após esse processo, determinaram-se as matérias secas dos limbos e dos pecíolos das folhas, dos rizomas, das raízes e das inflorescências.

O material vegetal seco foi moído em moinho tipo Willey para a determinação química do boro. O teor de boro, após digestão via seca, foi determinado por colorimetria (método da curcumina) (Malavolta et al., 1997).

O acúmulo de boro nas folhas (limbos e pecíolos), nos rizomas, nos sistemas radiculares e nas inflorescências foram determinados multiplicando-se o teor de boro pela matéria seca correspondentes. A translocação (\%) de boro foi obtida pela razão entre o acúmulo de boro na parte aérea e o acúmulo total de boro na planta, onde o acúmulo de boro na parte aérea corresponde ao acúmulo nas folhas e o acúmulo total de boro na planta é a soma dos acúmulos nas folhas, no rizoma, nas raízes e nas inflorescências. A exportação $(\%)$ de boro pelas inflorescências foi determinada pela divisão entre o acúmulo de boro nas inflorescências e o acúmulo total de boro na planta.

Os dados obtidos foram submetidos à análise de variância e as médias comparadas pela análise de regressão polinomial com o auxílio do programa estatístico SISVAR (Ferreira, 2000). Os dados de número de brotos foram transformados com o uso da fórmula $\sqrt{x+1}$. 


\section{RESULTADOS E DISCUSSÃO}

As plantas de copo-de-leite não manifestaram sintomas visuais de deficiência ou de toxidez de boro em suas folhas, durante o período em que foram submetidas às doses de boro em solução nutritiva. Em todos os tratamentos, as plantas apresentaram florescimento. No entanto, o sistema radicular da planta cultivada na dose de $0,05 \mathrm{mg} \mathrm{L}^{-1}$ de boro teve o crescimento e desenvolvimento reduzidos, em comparação ao das plantas cultivadas nas demais doses (Figura 1).

Em relação à altura, as plantas de copo-de-leite desenvolvidas nas doses de 0,05 a $2,00 \mathrm{mg} \mathrm{L}^{-1}$ de boro apresentaram diferenças, sendo que a maior altura foi de $71,10 \mathrm{~cm}$, na dose estimada de 1,05 $\mathrm{mg} \mathrm{L}^{-1}$ (Figura 2). Resultado semelhante foi obtido por Silveira et al. (2000) em eucalipto cultivado sob doses de boro em solução nutritiva. No entanto, em experimento com cultivares de trigo desenvolvidas sob doses de boro em solução nutritiva, Furlani et al. (2003) não observaram diferenças significativas na altura das plantas.
O número de folhas, a largura de folha e o comprimento de pecíolo da folha de plantas de copo-deleite não apresentaram diferenças em função das doses de boro, sendo em média 5,95; 24,77 cm e $65,18 \mathrm{~cm}$, respectivamente. Para comprimento de folha, a dose de 1,03 $\mathrm{mg} \mathrm{L}^{-1}$ de boro proporcionou $29,10 \mathrm{~cm}$ de comprimento, sendo essa a maior dimensão estimada (Figura 2).

$\mathrm{O}$ diâmetro do rizoma e o número de brotos em plantas de copo-de-leite não apresentaram diferenças em função das doses de boro testadas, com médias gerais de 2,79 cm e 1,51, respectivamente. Em plantas de paricá desenvolvidas sob doses de boro, Lima et al. (2003) observaram que o diâmetro do caule também não teve um incremento acentuado entre as doses aplicadas, porém, o decréscimo em diâmetro teve início na dose $0,07 \mathrm{mg} \mathrm{dm}^{-3}$. No entanto, em plantas de eucalipto, Silveira et al. (2000) constataram que as doses de boro causaram diferenças significativas no diâmetro, e observou-se também que o número de brotos não diferiu, assim como não ocorreu em copo-de-leite.
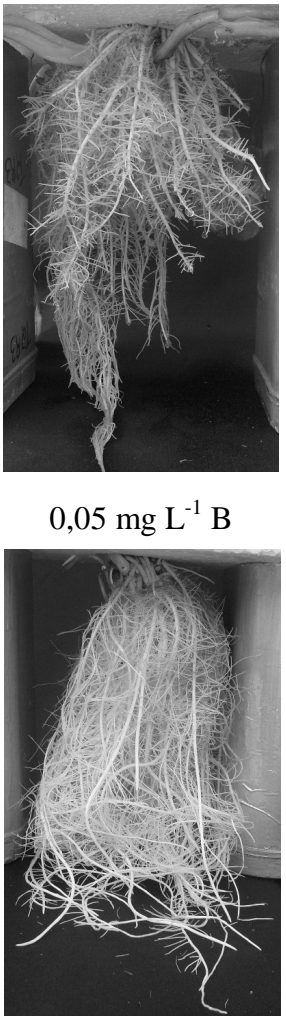

$0,75 \mathrm{mg} \mathrm{L}^{-1} \mathrm{~B}$

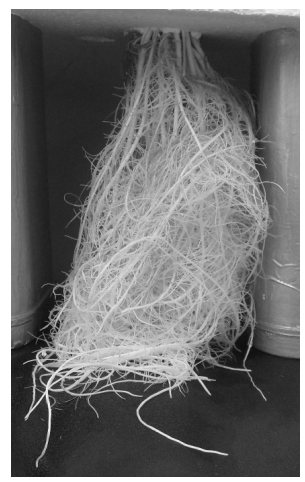

$0,25 \mathrm{mg} \mathrm{L}^{-1} \mathrm{~B}$

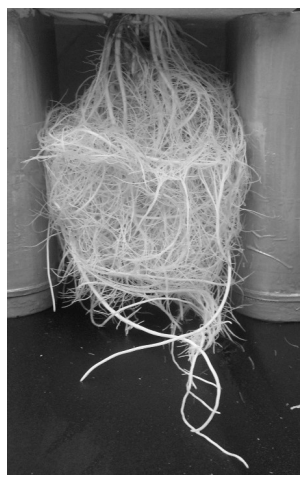

$1,00 \mathrm{mg} \mathrm{L}^{-1} \mathrm{~B}$

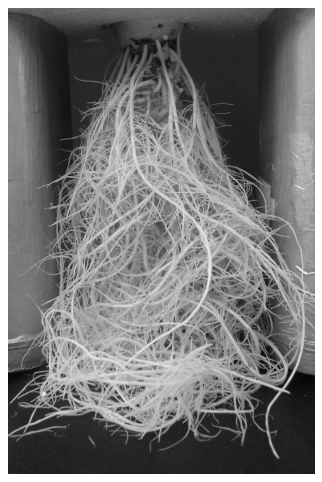

$0,50 \mathrm{mg} \mathrm{L}^{-1} \mathrm{~B}$

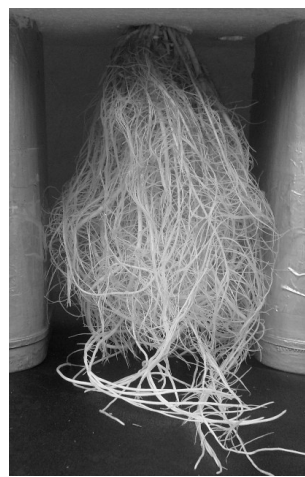

$2,00 \mathrm{mg} \mathrm{L}^{-1} \mathrm{~B}$

Figura 1 - Aspecto geral do sistema radicular de plantas de copo-de-leite cultivadas sob doses de boro em solução nutritiva, após 210 dias. 

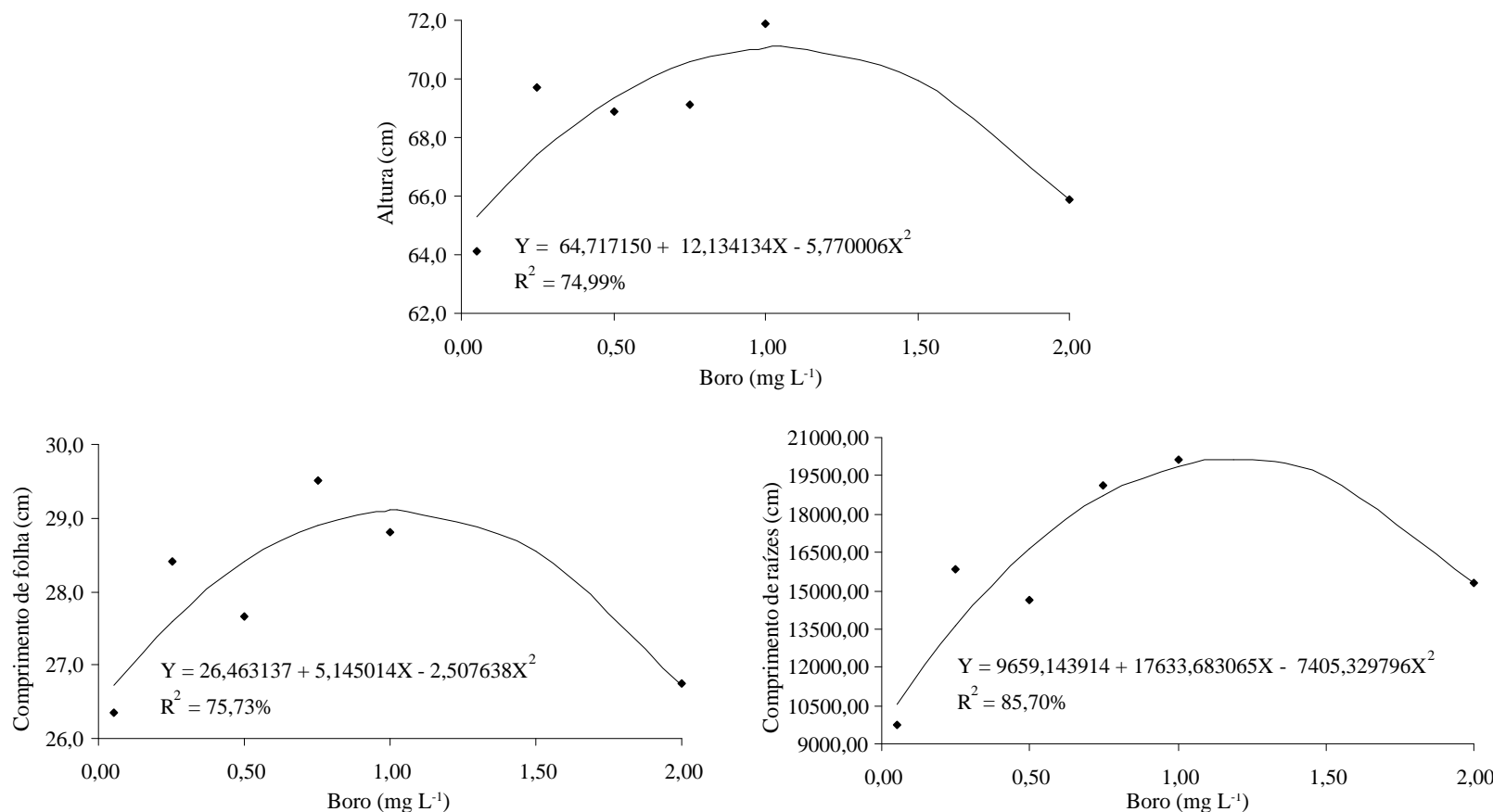

Figura 2 - Altura, comprimento de folha e comprimento total de raízes em plantas de copo-de-leite cultivadas sob doses de boro em solução nutritiva, após 210 dias.

O comprimento total radicular corresponde ao somatório do comprimento de todos os eixos radiculares formados, sendo que o maior comprimento radicular estimado foi de $20.156,54 \mathrm{~cm}$, na dose de $1,19 \mathrm{mg} \mathrm{L}^{-1}$ de boro (Figura 2). Esse parâmetro é um indicador do potencial de absorção de água e nutrientes pelas plantas no substrato de cultivo, sendo que a melhor exploração do substrato ocorre quanto maior for o comprimento total de raízes (Zonta et al., 2006). Ao testar diferentes concentrações de boro no cultivo de cultivares de arroz em solução nutritiva, Pavinato et al. (2009) verificaram decréscimo no comprimento radicular com o aumento da concentração de boro.

As características avaliadas nas inflorescências produzidas de copo-de-leite durante os 210 dias de cultivo em solução nutritiva não apresentaram diferenças comparando-se as doses de boro aplicadas.

As matérias frescas dos limbos foliares, dos pecíolos, das folhas inteiras, do rizoma e da planta não mostraram diferenças em função das doses de boro testadas, sendo de, respectivamente, 97,06; 243,77; 340,83; 31,29 e 493,93 g. No entanto, a matéria fresca do sistema radicular das plantas de copo-de-leite apresentou diferença, sendo que o incremento em matéria fresca ocorreu até a dose estimada de $1,17 \mathrm{mg} \mathrm{L}^{-1}$ de boro, com o ganho máximo de 162,86 g (Figura 3).
As matérias secas dos limbos foliares, pecíolos, folhas inteiras, rizoma, inflorescência e da planta não tiveram diferenças em relação às diferentes doses de boro. Resultados semelhantes foram obtidos por Salvador et al. (2003) em goiabeira, para o acúmulo de matéria seca nas folhas, nos caules e nas plantas. No entanto, em plantas de paricá, Lima et al. (2003), observaram diferentes ganhos em matéria seca da parte aérea em função das doses de boro testadas em solução nutritiva.

Contudo, a matéria seca do sistema radicular das plantas de copo-de-leite diferiu em relação às doses de boro adicionadas à solução nutritiva, sendo que, maior incremento, foi de 3,54 g na dose estimada de $1,18 \mathrm{mg} \mathrm{L}^{-1}$ de boro (Figura 3). Em mamoneira, Silva et al. (2008), verificaram que as plantas cultivadas na ausência de boro apresentaram menor teor de matéria seca de raízes em comparação com as demais doses testadas desse nutriente em solução nutritiva. Resultado semelhante foi observado por Sheng et al. (2009), em laranjeira Newhall (Citrus sinensis (L.) Osbeck) enxertada em Poncirus trifoliata Rafin cultivada sob diferentes concentrações de boro adicionadas à solução nutritiva aplicada no substrato, em que ocorreu acréscimo na matéria seca de raízes com o aumento do boro disponível para a planta. 
O teor de boro nas folhas de copo-de-leite aumentou até a dose de $1,10 \mathrm{mg} \mathrm{L}^{-1}$, com o valor de 40,60 $\mathrm{mg} \mathrm{kg}^{-1}$ na matéria seca (Figura 4). Em eucalipto cultivado sob doses de boro em solução nutritiva, Silveira et al. (2000), constataram que o teor de boro nas folhas respondeu de forma linear crescente, de acordo com as doses de boro aplicadas. Resultados semelhantes foram obtidos por Lima et al. (2003), em paricá, e por Salvador et al. (2003) em goiabeira.

O suprimento adequado de boro para o bom desenvolvimento das plantas cultivadas difere quanto à exigência desse micronutriente nas diferentes espécies vegetais, levando em consideração a composição química das paredes celulares (Marschner, 1995). As concentrações de boro entre 30 e $50 \mathrm{mg} \mathrm{kg}^{-1}$ na matéria seca são consideradas adequadas para um crescimento normal das plantas, sendo que nas deficientes, as concentrações foliares encontradas são inferiores a $15 \mathrm{mg} \mathrm{kg}^{-1}$ (Dechen \& Nachtigall, 2006).

$\mathrm{O}$ teor de boro no rizoma teve acréscimo até a dose estimada de $1,33 \mathrm{mg} \mathrm{L}^{-1}$ de boro, com 21,50 $\mathrm{mg} \mathrm{kg}^{-1}$ na matéria seca (Figura 4).
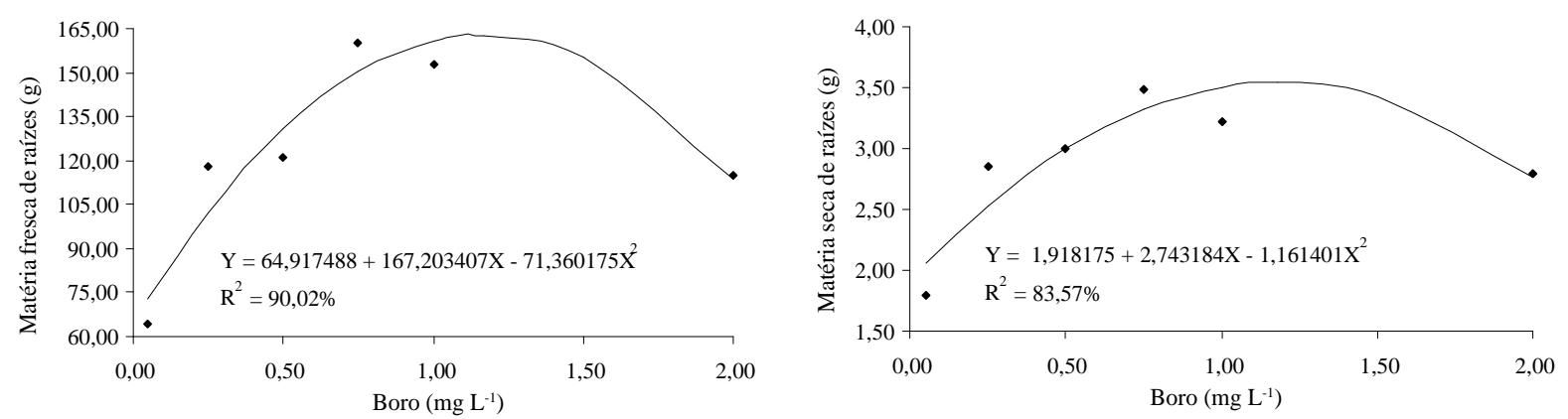

Figura 3 - Matérias fresca e seca de raízes de plantas de copo-de-leite cultivadas sob doses de boro em solução nutritiva, após 210 dias.
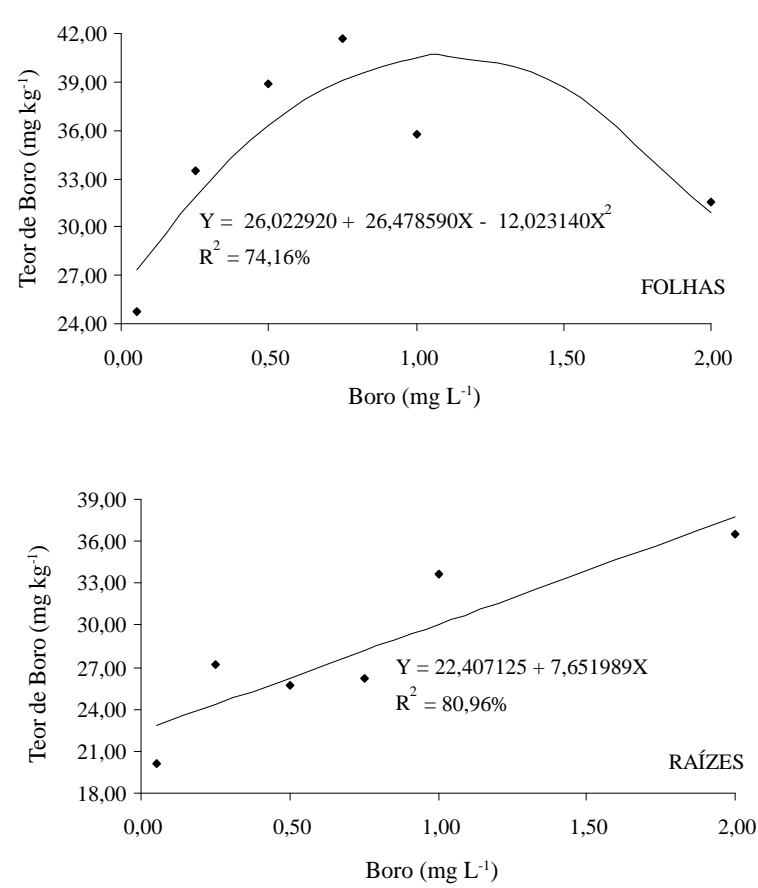
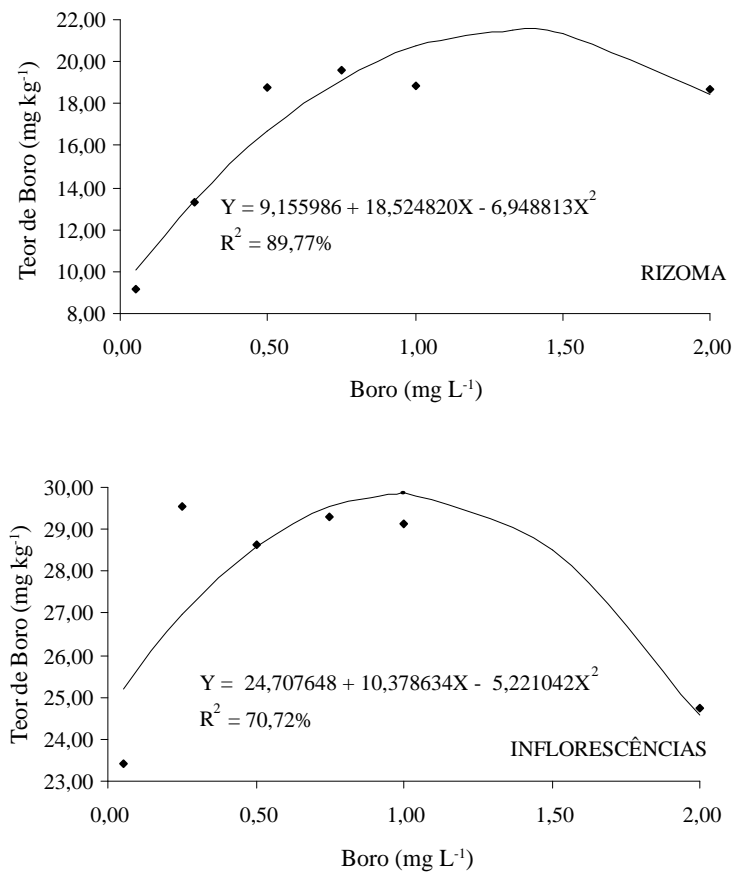

Figura 4 - Teores de boro ( $\mathrm{mg} \mathrm{kg}^{-1}$ ) nas folhas, no rizoma, nas raízes e nas inflorescências produzidas de copo-de-leite cultivado sob doses de boro em solução nutritiva. 
O incremento no teor de boro nas raízes ocorreu de forma linear. Assim, quanto maior a dose aplicada, maior foi o ganho no teor de boro, atingindo o valor de $37,71 \mathrm{mg} \mathrm{kg}^{-1}$ na matéria seca, na dose de 2,00 $\mathrm{mg} \mathrm{L}^{-1}$ de boro (Figura 4). Resultado semelhante foi obtido por Furlani et al. (2003), em cultivares de trigo. O boro em solução chega até a área de absorção radicular por fluxo de massa, e, em decorrência desse transporte passivo, é possível que ocorra absorção de quantidades tóxicas de boro pelo sistema radicular das plantas quando a concentração desse nutriente na solução é elevada (Dechen \& Nachtigall, 2006).

O maior teor de boro nas inflorescências foi obtido na dose estimada de 0,99 $\mathrm{mg} \mathrm{L}^{-1}$ de boro, com 29,87 $\mathrm{mg} \mathrm{kg}^{-1}$ na matéria seca (Figura 4).

Os acúmulos de boro nas folhas, no rizoma, no sistema radicular e nas inflorescências de copo-de-leite foram diferentes em função das doses de boro testadas na solução nutritiva (Figura 5).

O maior acúmulo de boro nas folhas ocorreu na dose estimada de 1,04 $\mathrm{mg} \mathrm{L}^{-1}$ de boro, com acúmulo de 982,90 $\mu \mathrm{g}$ planta $^{-1}$. No rizoma, o maior acúmulo foi obtido na dose estimada de 1,27 mg L-1, com 78,99 $\mu \mathrm{g}$ planta $^{-1}$ de boro, e nas raízes, o acúmulo máximo de boro, $115,01 \mu \mathrm{g}$ planta ${ }^{-1}$, ocorreu na dose estimada de 1,43 $\mathrm{mg} \mathrm{L}^{-1}$. Nas inflorescências, o acúmulo de boro aumentou até a dose de $1,05 \mathrm{mg} \mathrm{L}^{-1}$, sendo de 106,19 $\mu \mathrm{g}$ planta $^{-1}$. Comparando os acúmulos de boro obtidos nos órgãos das plantas de copo-de-leite em função das doses de boro, nota-se que as folhas tiveram um acúmulo maior, sendo esse o órgão que mais acumula boro (Sotiropoulos et al., 1999).

A translocação de boro em copo-de-leite desenvolvido em solução nutritiva com adição de doses de boro foi diferente, sendo que essa diminuiu linearmente em função das doses aplicadas, com translocação média de $79,21 \%$ na dose de $0,05 \mathrm{mg} \mathrm{L}^{-1}$ e de $71,80 \%$ na dose de $2,00 \mathrm{mg} \mathrm{L}^{-1}$ (Figura 6).

O boro, na maioria das plantas, não é redistribuído das folhas ou de outros órgãos para suprir as necessidades do crescimento. Esse micronutriente é translocado na planta, principalmente, pelo xilema, sendo a mobilidade no floema muito limitada. Assim, o boro é acumulado nas folhas velhas e a parte aérea das plantas concentra mais boro do que o sistema radicular (Dechen \& Nachtigall, 2006; Malavolta, 2006).

A exportação de boro pelas inflorescências foi menor na dose estimada $1,14 \mathrm{mg} \mathrm{L}^{-1}$, com 8,38\% desse micronutriente exportado por esse órgão (Figura 6). Em doses menores e superiores a $1,14 \mathrm{mg} \mathrm{L}^{-1}$ de boro, pode-se inferir que houve uma maior concentração de boro nas inflorescências emitidas. Em doses menores, a causa dessa maior exportação pode ter ocorrido para suprir a necessidade de boro pelas inflorescências, para que essas suportassem uma possível deficiência desse nutriente. Já, em doses superiores, a maior exportação pode ter sido por causa de um possível fornecimento elevado de boro no cultivo de copo-de-leite.
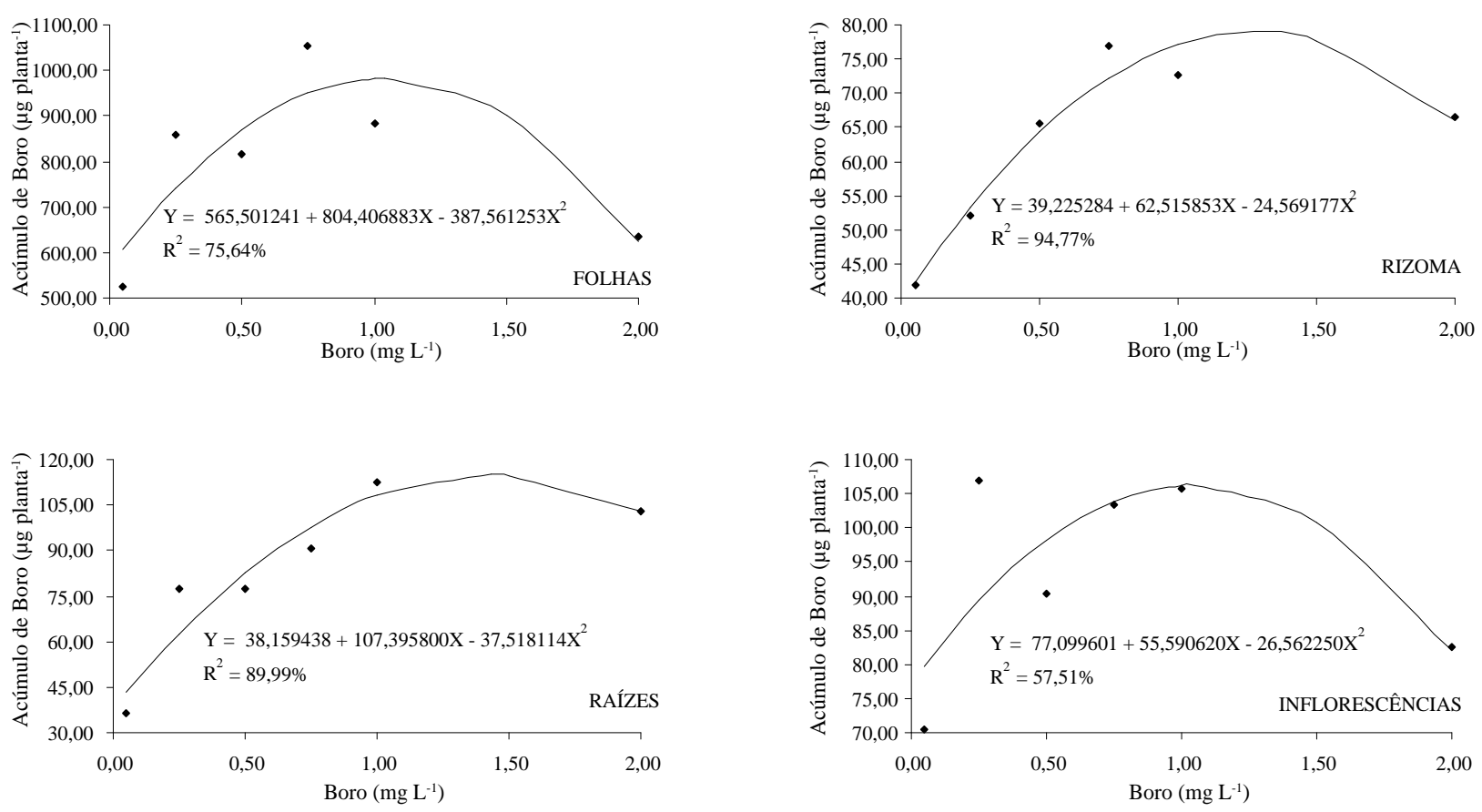

Figura 5 - Acúmulos de boro ( $\left.\mu \mathrm{g}_{\text {planta }}{ }^{-1}\right)$ nas folhas, no rizoma, nas raízes e nas inflorescências produzidas de copode-leite cultivado sob doses de boro em solução nutritiva. 

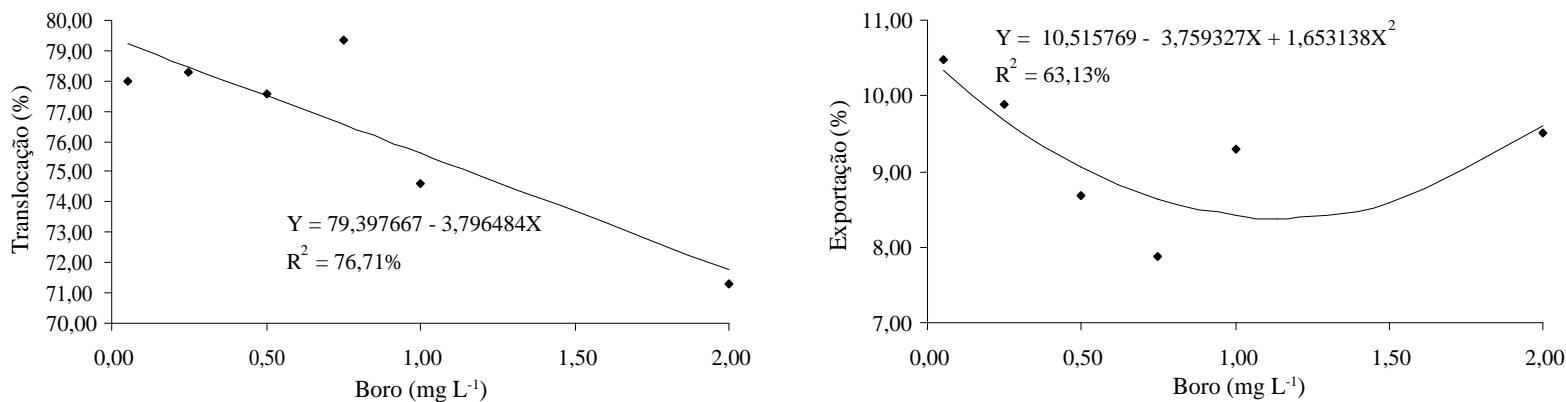

Figura 6 - Translocação nas plantas e exportação pelas inflorescências de boro em copo-de-leite cultivado sob doses de boro em solução nutritiva.

\section{CONCLUSÕES}

A parte aérea e as inflorescências produzidas de copo-de-leite cultivado nas doses de 0,05 a $2,00 \mathrm{mg} \mathrm{L}^{-1} \mathrm{de}$ boro não manifestaram sintomas visuais de deficiência ou de toxidez desse micronutriente.

As raízes desenvolvidas na dose de $0,05 \mathrm{mg} \mathrm{L}^{-1}$ de boro em solução nutritiva tiveram o crescimento reduzido.

A melhor dose para o desenvolvimento adequado de copo-de-leite em solução nutritiva é de $1,20 \mathrm{mg} \mathrm{L}^{-1}$ de boro.

\section{REFERÊNCIAS BIBLIOGRÁFICAS}

DECHEN, A.R.; NACHTIGALL, G.R. Micronutrientes. In: FERNANDES, M. (Ed.). Nutrição mineral de plantas. Viçosa, MG: Sociedade Brasileira de Ciência do Solo, 2006. p.327-354.

FERREIRA, D.F. Análises estatísticas por meio do Sisvar para Windows versão 4.0. In: REUNIÃO ANUAL DA REGIÃO BRASILEIRA DA SOCIEDADE INTERNACIONAL DE BIOMETRIA, 45., 2000, São Carlos. Anais... São Carlos: UFSCar, 2000. p.255-258.

FURLANI, A.M.C.; CARVALHO, C.P.; FREITAS, J.G.; VERDIAL, M.F.V. Wheat cultivar tolerance to boron deficiency and toxicity in nutrient solution. Scientia Agricola, Piracicaba, v.60, n.2, p.359-370, Apr./June 2003.

HOAGLAND, D.R.; ARNON, D.I. The water culture method for growing plants without soils. Berkeley: The College of Agriculture University of California; California Agricultural Experimental Station, 1950. 32p. (Circular, 347).

LIMA, S.F.; CUNHA, R.L.; CARVALHO, J.G.; SOUZA, C.A.Z.; CORREAA, F.L.O. Comportamento do paricá
(Schizolobium amazonicum Herb.) submetido à aplicação de doses de boro. Cerne, Lavras, v.9, n.2, p.192-204. jul./dez. 2003.

MALAVOLTA, E. Manual de nutrição mineral de plantas. São Paulo: Agronômica Ceres, 2006. 638p.

MALAVOLTA, E.; VITTI, G.C.; OLIVEIRA, S.A. Metodologia para análise de elemento em material vegetal. In: . Avaliação do estado nutricional das plantas: princípios e aplicações. 2.ed. Piracicaba: Associação Brasileira para Pesquisa da Potassa e do Fosfato, 1997. p.231-307.

MARSCHNER, H. Mineral nutrition of higher plants. 2.ed. New York: Academic, 1995. 889p.

MORAES-DALLAQUA, M.A.; BELTRATI, C.M.; RODRIGUES, J.D. Anatomia de ápices radiculares de feijão cv. carioca submetidos a níveis de boro em solução nutritiva. Scientia Agricola, Piracicaba, v.57, n.3, p.425-430, jul./set. 2000.

NOWAK, J.; RUDNICKI, R.M. Postharvest handling and storage of cut flowers, florist greens and potted plants. Portland: Timber, 1990. 210p.

PAVINATO, P.S.; AGUIAR, A.; CASTRO, G.S.A.; CRUSCIOL, C.A.C. Boro em arroz de terras altas cultivado em solução nutritiva. Bragantia, Campinas, v.68, n.3, p.743-751, set. 2009

PEGORARO, R.F.; SANTOS NETO, J.A.; SILVA, I.R.; FONTES, R.L.F.; FARIA, A.F.; MOREIRA, F.F.

Crescimento de soja em solos em resposta a doses de boro, calagem e textura do solo. Ciência e agrotecnologia, Lavras, v.32, n.4, p.1092-1098, jul./ago. 2008. 
RÉGENT INSTRUMENTS. Imagem Analysis Systems for Plant Science WinRHIZO ${ }^{\circledR}$. Ottawa, 2004. Disponível em: <htttp:///www.regentinstruments.com Acesso em: 4 fev. 2009.

SALINGER, J.P. Producción comercial de flores. Zaragoza: Acribia, 1991.371p.

SALVADOR, J.O.; MOREIRA, A.; MALAVOLTA, E.; CABRAL, C.P. Influência do boro e do manganês no crescimento e na composição mineral de mudas de goiabeira. Ciência e Agrotecnologia, Lavras, v.27, n.2, p.325-331, mar./abr. 2003.

SHENG, O.; SONG, S.; PENG, S.; DENG, X. The effects of low boron on growth, gas exchange, boron concentration and distribution of "Newhall" navel orange (Citrus sinensis Osb.) plants grafted on two rootstocks. Scientia Horticulturae, Amsterdam, v.121, n.3, p.278-283, July 2009.

SILBERBUSH, M.; LIETH, J.H. Nitrate and potassium uptake by greenhouse roses (Rosa hybrida) along successive flower-cut cycles: a model and its calibration.
Scientia Horticulturae, Amsterdam, v.101, n.1/2, p.127141, May 2004.

SILVA, D.H.; ROSSI, M.L.; BOARETTO, A.E.; NOGUEIRA, N.L.; MURAOKA, T. Boron affects the growth and ultrastructure of castor bean plants. Scientia Agricola, Piracicaba, v.65, n.6, p.659-664, Nov./Dec. 2008.

SILVEIRA, R.L.V.A.; TAKAHASHI, E.N.; SGARBI, F.; CAMARGO, M.A.F.; MOREIRA, A. Crescimento e estado nutricional de brotações de Eucalyptus citriodora sob doses de boro em solução nutritiva. Scientia Forestalis, Piracicaba, n.57, p.53-67, jun. 2000.

SOTIROPOULOS, T.E.; THERIOS, I.N.; DIMASSI, K.N. Calcium application as a means to improve tolerance of kiwifruit (Actinidia deliciosa L.) to boron toxicity. Scientia Horticulturae, Amsterdam, v.81, n.4, p.443-449, Oct. 1999.

ZONTA, E.; BRASIL, F.C.; GOI, S.R.; ROSA, M.T. O sistema radicular e suas interações com o ambiente edáfico. In: FERNANDES, M. (Ed.). Nutrição mineral de plantas. Viçosa, MG: Sociedade Brasileira de Ciência do Solo, 2006. p.7-52. 